\title{
OLHARES DO SUL DE MOÇAMBIQUE POR UM GEÓGRAFO BRASILEIRO
}

\author{
VIEWS OF SOUTH MOZAMBIQUE BY A BRAZILIAN GEOGRAPHER
}

"Quem dança não é aquele que levanta poeira. Quem dança é aquele que inventa seu próprio chão"

(Provérbio moçambicano)

\section{RESUMO}

Este artigo foi produzido com informações coletadas no período de março a abril de 2014 em que estivemos participando do estágio referente ao Projeto: Práticas sociais e saberes de mulheres e homens e a produção do território rural no Distrito de Marracuene em Moçambique: viabilidade das alternativas produtivas no mundo da sustentabilidade com aprovação do edital CAPES/AULP. A cartografia do trabalho de campo evidenciou a riqueza cultura do povo moçambicano e os contrastes existentes na parte sul do país. Complementando apresentamos alguns dados demográficos das províncias entendendo que estas informações sirvam de base para professores utilizarem em sala de aula, visto que o material didático existente sobre o país no Brasil é muito incipiente. Por fim fica evidente o papel que a ciência/pesquisa proporciona na vida das pessoas, pois foram experiências fantásticas de trocas entre pesquisadores brasileiros e moçambicanos durante o período do projeto e os frutos gerados permanecerá na academia por muito tempo.

Palavras-chave: Geografia, Cartografia, Moçambique, Brasil, Pesquisa

\section{ABSTRACT}

This article was produced with information collected from March to April 2014 when we were participating in the internship related to the Project: Social practices and knowledge of women and men and the production of rural territory in the Marracuene District in Mozambique: viability of productive alternatives in the world of sustainability with the approval of the CAPES / AULP notice. The cartography of the fieldwork showed the richness of the Mozambican people and the contrasts that exist in the southern part of the country. In addition, we present some demographic data from the provinces, understanding that this information serves as a basis for teachers to use in the classroom, since the existing teaching material about the country in Brazil is incipient. Finally, the role that science / research provides in people's lives is evident, as they were fantastic experiences of exchanges between Brazilian and Mozambican researchers during the project period and the fruits generated will remain in the academy for a long time.

Keywords: Geography, Cartography, Mozambique, Brazil, Research.
Angelo Franco do N. Ribeiro ${ }^{a}$

a Universidade Federal da Grande Dourados (UFGD), Dourados, MS, Brasil

DOI: $10.12957 /$ geouerj.2020.53703

Correpondência: angeloribeiro@ufgd.edu.br

Recebido em: 15 mai. 2019

Revisado em: 11 mar. 2020

Aceito em: 4 abr. 2020 


\section{INTRODUÇÃO}

Este artigo é resultado do período de março a abril de 2014 em que estivemos participando do estágio referente ao Projeto: Práticas sociais e saberes de mulheres e homens e a produção do território rural no Distrito de Marracuene em Moçambique: viabilidade das alternativas produtivas no mundo da sustentabilidade com aprovação do edital CAPES/AULP sob coordenação do Professor Edvaldo Cesar Moretti.

Uma experiência desta natureza começa antes da partida, com a imaginação do que encontraríamos, de como seria este outro lugar, o estudo de preparação que nos faz viajar com os textos e novas descobertas de um continente ainda desconhecido pelos membros da equipe. A expectativa, para não dizer apreensão é ainda maior, pois esta seria a primeira expedição deste projeto de pesquisa rumo ao outro lado do Atlântico, mais precisamente as margens do Índico na África Austral.

Além deste fato do conhecimento prévio tinha a partida para um outro país distante e de avião, que no meu caso seria a primeira viagem longa, deixando esposa e filho de 5 meses. Tudo isso tornou-se um desafio que estava decidido a viver e observar cada detalhe para que minha formação em Geografia tivesse mais este capítulo de busca para além das fronteiras latinas.

Trabalharemos neste recorte com a localização das atividades bem como a descrição de dados populacionais de Moçambique, sob o ponto de vista da Geografia, e daquilo que encontramos em um mês de pesquisa e vivência neste país tão peculiar e rico culturalmente. As informações contidas neste texto são originárias dos levantamentos de campo realizados durante o estágio e em fontes do Governo de Moçambique.

\section{Localização e contexto no continente Africano}

O país de Moçambique está localizado na costa oriental da África Austral e tem como limites: ao norte, Tanzânia; a noroeste, Malawi e a Zâmbia; a oeste, Zimbábwe, África do Sul e Suazilândia; ao sul, a África do Sul e a leste o Oceano Índico que nesta porção entre o continente e a llha de Madagascar é designada por Canal de Moçambique. A capital de Moçambique é Maputo que fica situada no extremo sul do país na província de mesmo nome. 
Figura 1. Localização de Moçambique e suas províncias

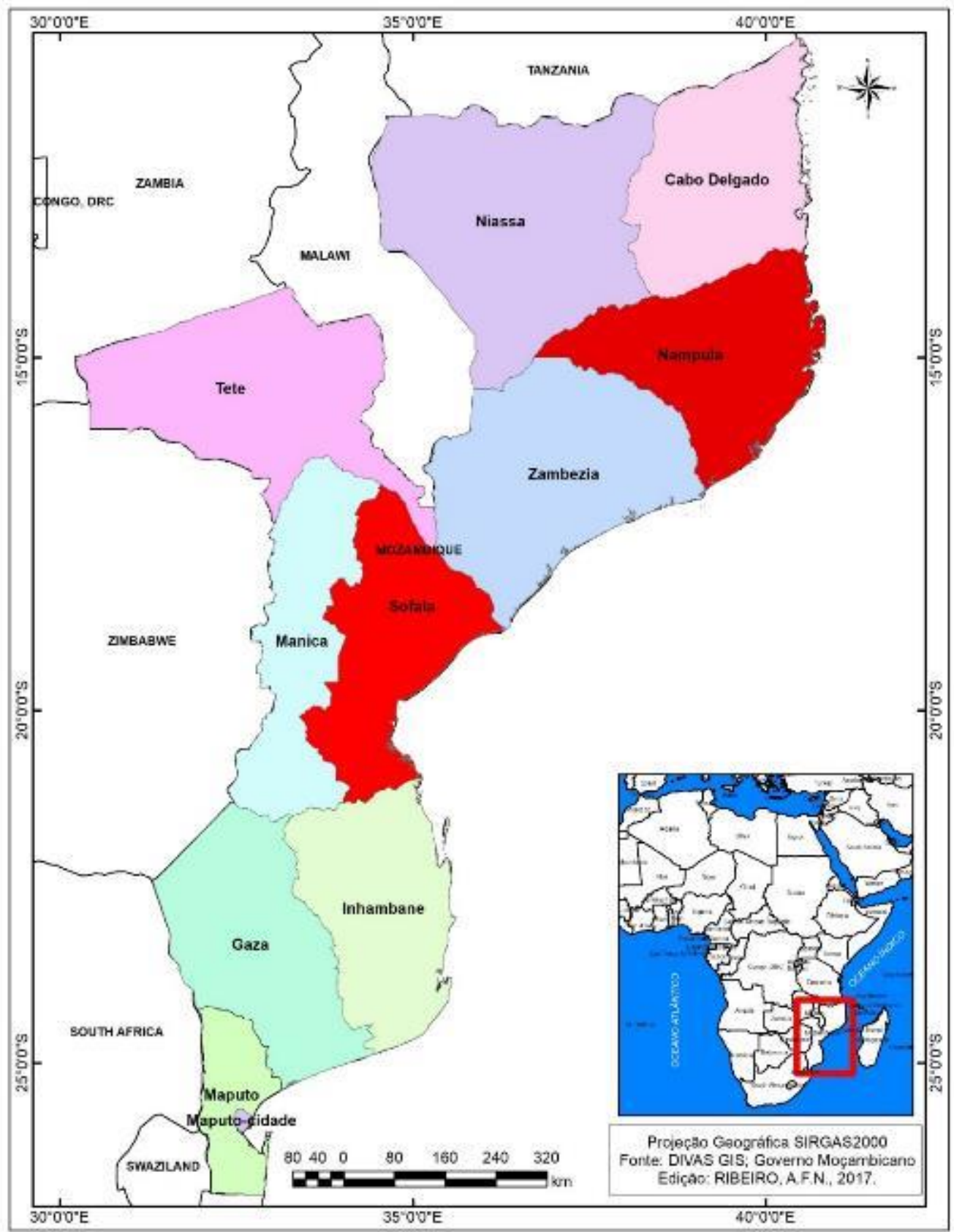

A porção ao norte é um grande planalto, com uma pequena planície costeira margeada de recifes de coral, limitando no interior com maciços montanhosos. A metade sul é caracterizada por uma larga planície costeira de aluvião, coberta por savanas e cortada pelos vales de vários rios.

O país é dividido em 11 províncias: A norte Niassa, Cabo Delgado, Nampula, no centro Zambézia, Tete, Manica, Sofala e ao sul Inhambane, Gaza e Maputo. Estas províncias por sua vez estão subdivididas em 128 distritos, que se organizam em postos administrativos e estes em localidades, o nível mais baixo da administração local do Estado. 


\section{AS PROVÍNCIAS}

\section{Cabo Delgado}

A província de Cabo Delgado está situada no extremo norte de Moçambique, fazendo fronteira, a norte com o país da Tanzânia, da qual está separada pelo rio Rovuma, a oeste com a província do Niassa e com a província de Nampula a sul, na outra margem do rio Lúrio e a leste limita-se com o Oceano Índico.

A província de Cabo Delgado possui uma extensão de $82.625 \mathrm{~km}^{2}$ distribuídos em um conjunto de 17 distritos, incluindo a cidade de Pemba sua capital, os quais se encontram estruturados em 56 postos administrativos com 128 localidades e cerca de 796 aldeias. Possui uma população de pouco mais de 2 milhões de habitantes segundo o censo de 2017.

Niassa

A província de Niassa é a maior de Moçambique em termos de área, e está localizada na região norte de Moçambique, faz fronteira ao norte com a Tanzânia, a sul com as províncias de Nampula e Zambézia, com a província de Cabo Delgado a leste e a oeste com o Malawi, com o qual também divide o Lago Niassa, o terceiro maior da África.

Niassa está dividida em 16 distritos sendo Lichinga a capital da província, e 5 municípios. A população da província é de cerca de 1.800.000 habitantes distribuídos em uma área de $129056 \mathrm{~km}^{2}$.

\section{Nampula}

Localizada a nordeste de Moçambique com a capital de mesmo nome, faz fronteira a norte, através do rio Lúrio, com as províncias de Cabo Delgado e Niassa. A sudoeste está dividida pelo rio Ligonha da Zambézia, limitada a leste pelo Oceano Índico.

Nampula está dividida em 23 distritos e estes subdivididos por 7 municípios. Possui uma extensão territorial de $81.606 \mathrm{~km}^{2}$ e população de pouco mais de 6 milhões de habitantes é a província mais populosa do país. 


\section{Zambézia}

Está situada na região centro norte de Moçambique, limitada a norte pelas províncias de Nampula e Niassa e a leste pelo Canal de Moçambique no Oceano Índico e ao sul pela a província de Sofala. A oeste, pela província de Tete, e pelo Malawi. Sua capital é a cidade de Quelimane, que fica distante cerca de 1600 km de Maputo.

Possui uma área de $105.008 \mathrm{~km}^{2}$, está dividida em 22 distritos, e possui 6 municípios com uma população de aproximadamente 5 milhões de habitantes é a segunda província mais populosa de Moçambique.

Tete

A Província de Tete situa-se no extremo noroeste do país, e faz fronteira internacional com o Malawi e Zâmbia ao norte e com o Zimbabwe a oeste e a sul e as províncias Moçambicanas, Zambézia a leste, Manica e Sofala ao sul. Sua capital é a cidade de Tete.

Está dividida em 13 distritos, 34 postos administrativos e 3 municípios com extensão territorial de 100.724 km² e população aproximada de 2,8 milhões de habitantes.

\section{Manica}

Está localizada no centro oeste de Moçambique limitada a norte pela província de Tete a leste por Sofala e ao sul por Gaza e Inhabane, a oeste faz fronteira com o Zimbabwe. Sua capital é a cidade de Chimoio.

Manica possui extensão de $61.661 \mathrm{~km}^{2}$ onde estão distribuídos 12 distritos e 5 municípios com população aproximada de 2 milhões de habitantes.

\section{Sofala}

Situa-se na região central do país, com uma longa faixa de litoral a leste no canal de Moçambique, Oceano Índico e a norte e nordeste pelo rio Zambeze com as províncias de Tete e Zambézia, ao sul pelo rio Save com a província de Inhambane e a oeste com a província de Manica. 
A província situada no centro de Moçambique possui uma extensão de $68.018 \mathrm{~km}^{2}$ e população de aproximadamente 2 milhões de habitantes distribuídos em 12 distritos e 5 municípios.

\section{Gaza}

Localizada no sul do País sendo sua capital a cidade de Xai-Xai, que fica cerca de 210 km da capital Maputo. Gaza é atravessada pelo rio Limpopo, e ele torna a província importante sobre diferentes pontos de vista: agricultura, política e desenvolvimento. É limitada a norte pela província de Manica e a nordeste por Inhambane e ao sul pela província de Maputo, faz fronteira ao sul com a África do Sul e a oeste com o Zimbabwe e na porção sudeste possui litoral com o oceano Índico.

Conta com 14 distritos e 6 municípios em uma extensão de $75.709 \mathrm{~km}^{2}$ e população de aproximadamente 1,5 milhão de habitantes

\section{Inhambane}

Localizada na região sul de Moçambique, Inhambane está limitada a norte pelas províncias de Manica e Sofala, a leste e sudeste possui extenso litoral no oceano Índico e ao sul e oeste pela a província de Gaza. A sua capital é a cidade de Inhambane.

Sua divisão administrativa compõe 14 distritos e 5 municípios distribuídos em uma extensão territorial de $68.615 \mathrm{~km}^{2}$ e população de aproximadamente 1,5 milhão de habitantes.

\section{Maputo Província}

Sendo a mais meridional de Moçambique, a província de Maputo está limitada ao norte pela província de Gaza, a leste com o oceano Índico e com a cidade de Maputo ao sul, encontramos fronteira com a África do Sul e a oeste com a Suazilândia e África do Sul. Sua capital é a cidade de Matola distante apenas $10 \mathrm{~km}$ de Maputo.

Território de $26.058 \mathrm{~km}^{2}$ a província de Maputo conta com 8 distritos e possui 4 municípios para uma população de aproximadamente 2,5 milhões de habitantes. 


\section{Maputo Cidade}

Maputo é a capital de Moçambique e a maior cidade do país, está situada no extremo sul do país, às margens da baía de Maputo e a oeste pela província de Maputo. Em termos administrativos e políticos Maputo é um município, com governo eleito e, desde 1980, também uma província e possui 7 distritos. Faz parte desta província a Ilha de Inhaca que fica a leste da baía de Maputo.

É a menor província do país com apenas $300 \mathrm{~km}^{2}$ e população de aproximadamente 1 milhão de habitantes.

\section{População}

O país de Moçambique é relativamente pouco povoado com uma densidade demográfica de 35 habitantes por $\mathrm{km}^{2}$, com sua população de 28.861 .863 distribuídos em $799.380 \mathrm{~km}^{2}$. Do total da população estima-se que aproximadamente $60 \%$ vivem no campo e $40 \%$ nos aglomerados urbanos e 13.800 .857 são homens e 15.061 .006 são mulheres. De maneira mais detalhada segue a tabela 1 e figura 2.

Tabela 1. Distribuição da população por província e sexo. Fonte: Censo, 2017.

\begin{tabular}{cccc}
\hline Província & Homens & Mulheres & Total \\
\hline Cabo Delgado & 1.131 .236 & 1.202 .042 & 2.333 .278 \\
Gaza & 666.656 & 779.998 & 1.446 .654 \\
Inhambane & 687.102 & 809.722 & 1.496 .824 \\
Manica & 915.621 & 995.616 & 1.911 .237 \\
Maputo Cidade & 529.510 & 571.660 & 1.101 .170 \\
Maputo Província & 1.178 .487 & 1.328 .611 & 2.507 .098 \\
Nampula & 2.941 .344 & 3.161 .523 & 6.102 .867 \\
Niassa & 906.680 & 959.296 & 1.865 .976 \\
Sofala & 1.071 .830 & 1.149 .973 & 2.221 .803 \\
Tete & 1.349 .992 & 1.414 .177 & 2.764 .169 \\
Zambézia & 2.422 .399 & 2.688 .388 & 5.110 .787 \\
\hline
\end{tabular}


Figura 2. Distribuição da população por Província.

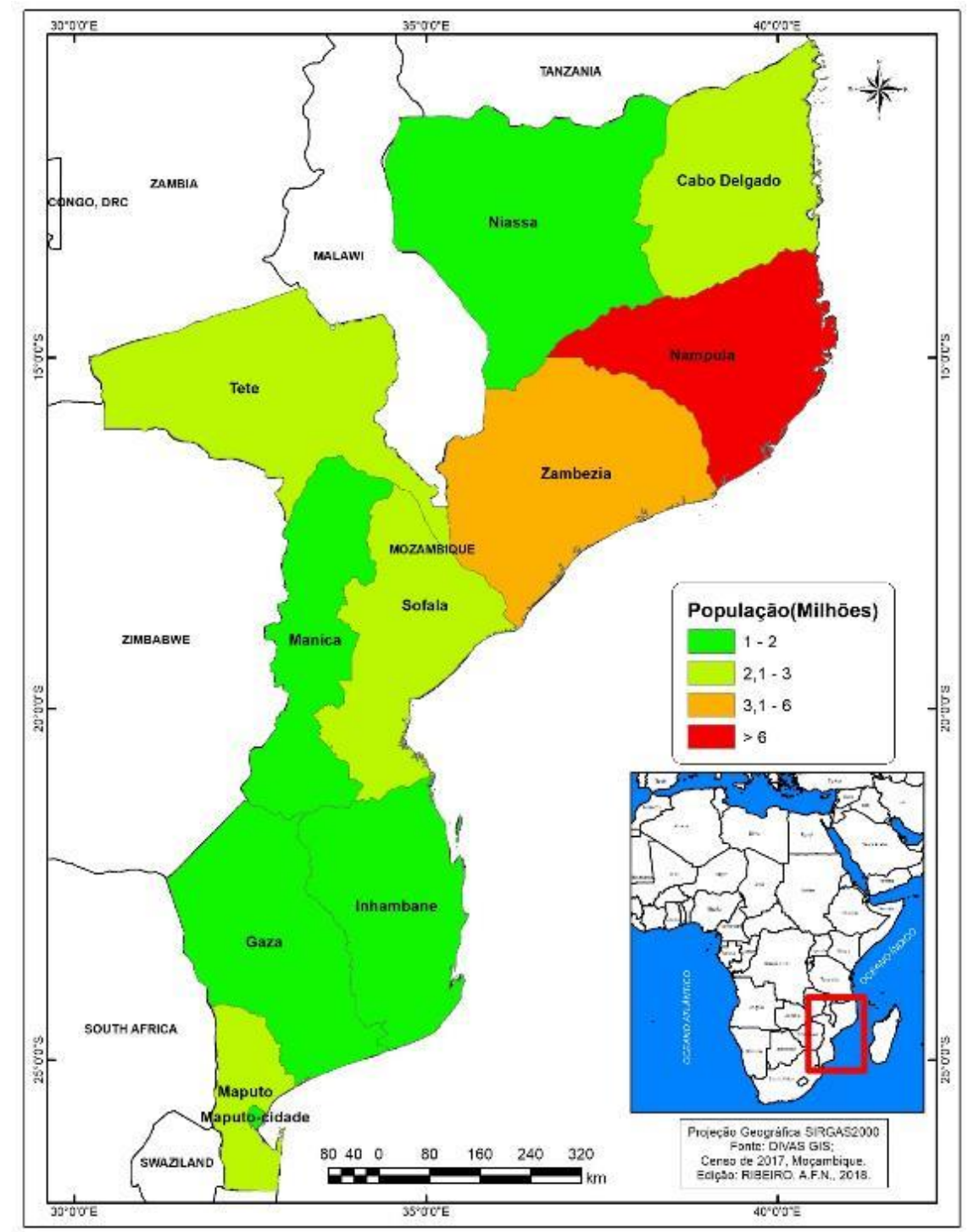

Algo que podemos perceber claramente na cidade de Maputo e que houve uma intensa migração para a cidade e os aparelhos urbanos não acompanharam este aumento populacional na mesma proporção, e desta forma alguns serviços se mostram ineficientes ou deficitários, como o caso de abastecimento de água e transporte coletivo.

\section{Vivência em Maputo}

Nossa expedição partiu do Brasil em direção a Moçambique, nesse que seria a primeira de duas estadas em terras moçambicanas, nesse momento o intuito era entender a dinâmica espacial neste recorte do projeto que era o distrito de Marracuene distante cerca de $20 \mathrm{Km}$ da capital Maputo em direção à Praia de Macaneta. 
Com todo o cansaço da viagem e confusão gerada pela diferença de horário que naquele período era de 6 horas, nos chama atenção as várias construções de grande porte na cidade, seja de infraestrutura ou prédios em bairros da cidade e também dentro da Universidade Eduardo Mondlane - UEM, onde ficamos hospedados, conforme figura 3 :

Figura 3. Construções de grande porte na cidade de Maputo. Fotos: RIBEIRO, A.F.N., 2014

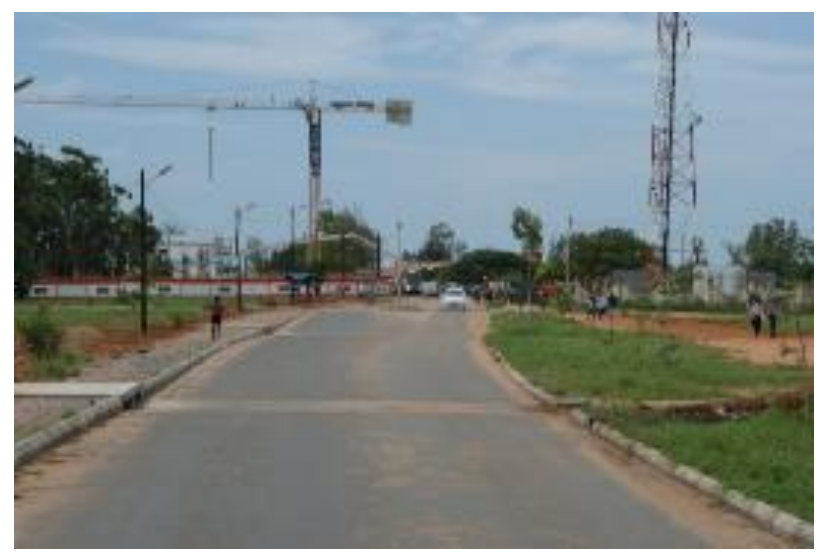

Universidade Eduardo Mondlane

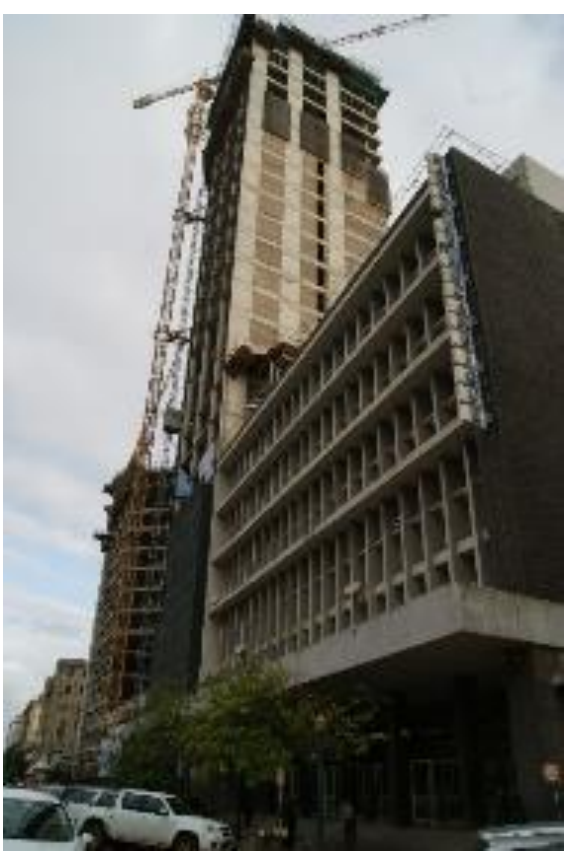

Centro de Maputo

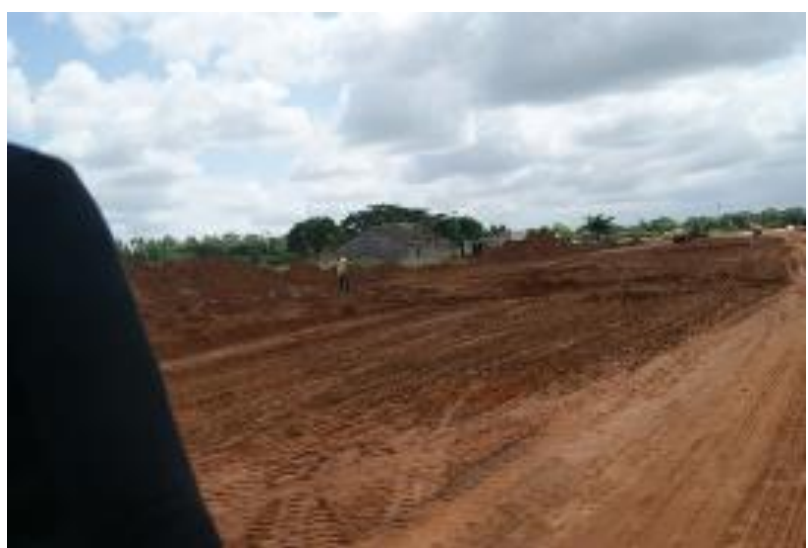

Circular de Maputo

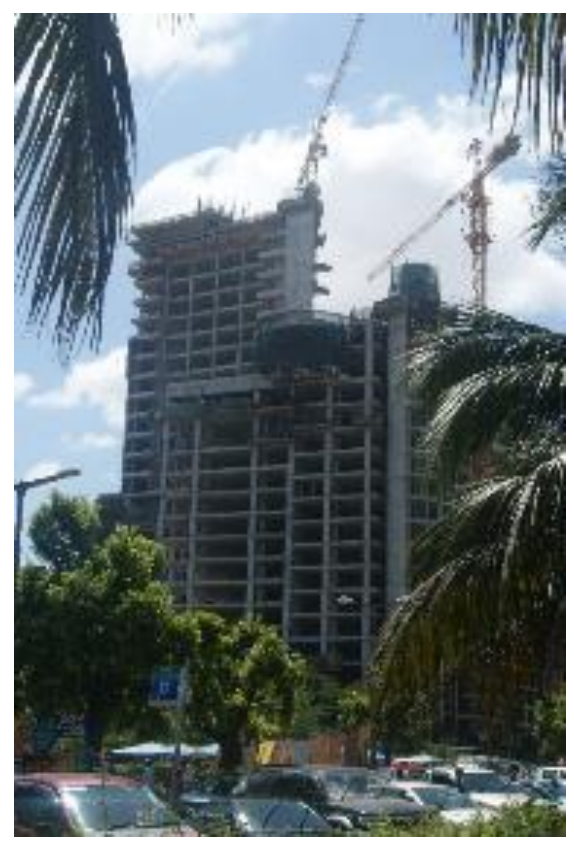

Bairro da Baixa

Além do aspecto relacionado a infraestrutura outro ponto muito forte e presente no quotidiano de Maputo é o artesanato, seja de madeira, ou nas variadas cores dos batiks e kapulanas nas suas mais variadas 
formas. O artesanato em madeira, principalmente de "pau preto", madeira típica que se diferencia pela cor negra assemelhando-se ao carvão.

Figura 4. Artesanatos expostos na Feira das Flores. Fotos: RIBEIRO, A.F.N., 2014.

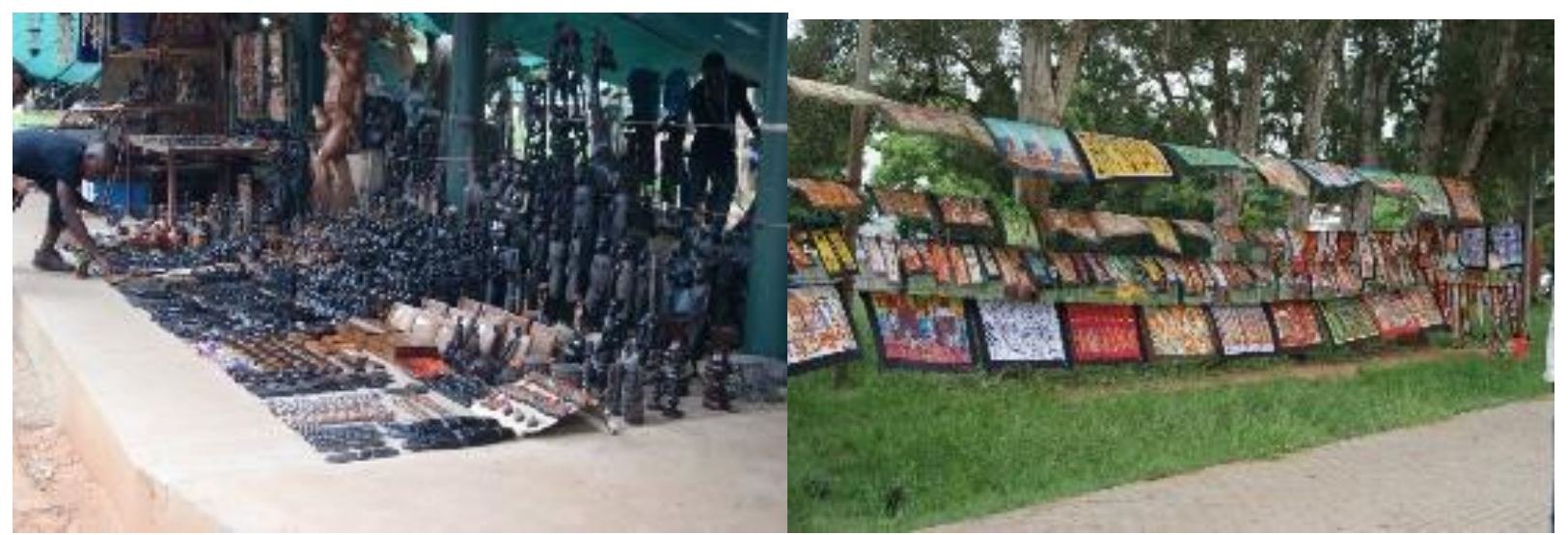

A Feira da Flores fica aberta todos os dias da semana com artesanato e praça de alimentação, nos finais de semana existe a Feira do Pau no bairro chamado Baixa, que fica próximo ao Porto, esta acontece na rua é dedicada ao artesanato em madeira e se chegar a feira dificilmente sairá sem comprar algo, tanto pela beleza das peças como pela insistência dos vendedores.

Figura 5. Feira do Pau na baixa Foto: RIBEIRO, A.F.N., 2014.

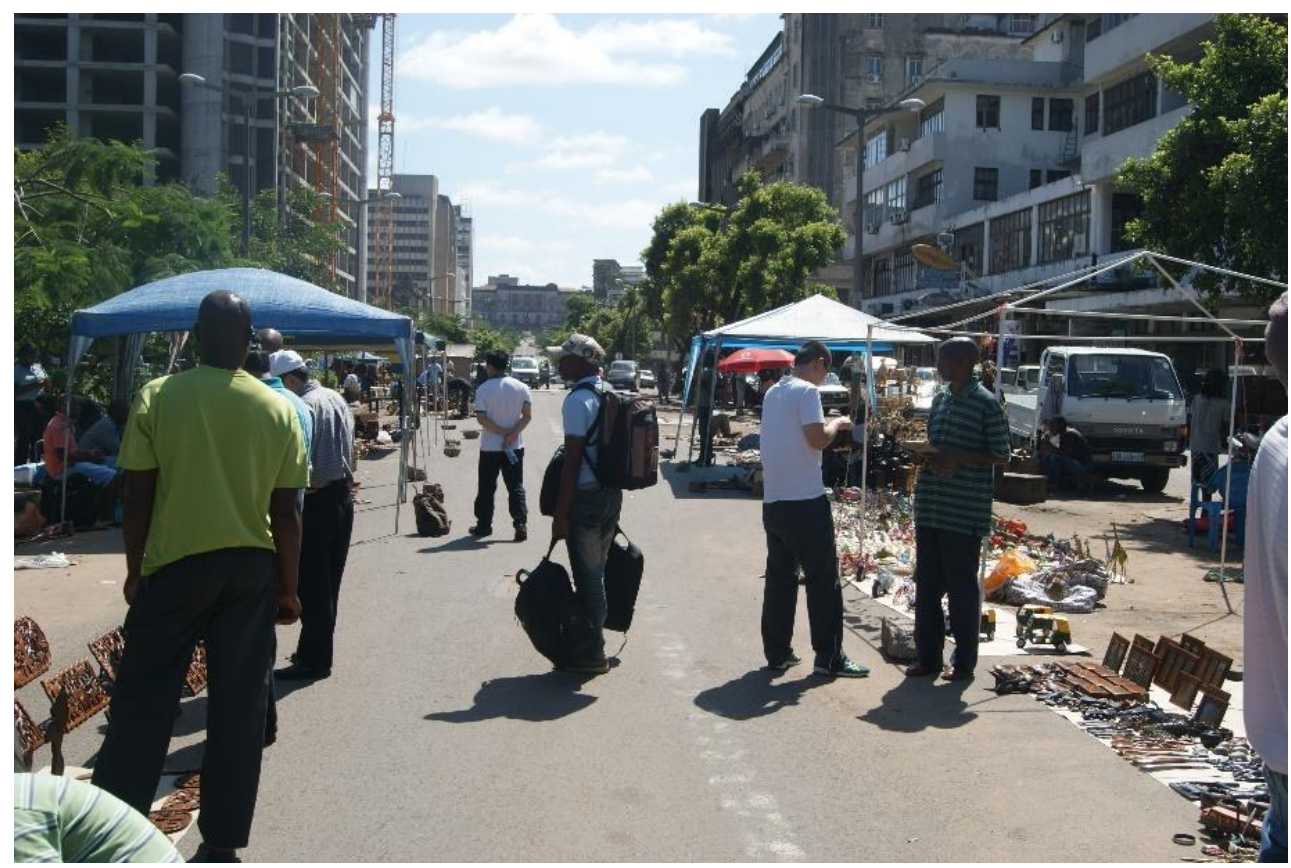


Após alguns dias em Maputo, conhecendo esta realidade, percebemos que o artesanato era algo muito característico, e passamos a buscar novas formas de entender a produção e comercialização destes bens tão peculiares e que servem de suvenir para os turistas que visitam a capital de Moçambique.

Outro aspecto marcante na cultura moçambicana é a comida com uma mistura de cores, temperos e iguarias como folhas de mandioca, abóbora e batata, a polenta de milho branco. Todas as comidas são temperadas com o piripiri (pimenta).

Figura 6. Moçambicana preparando a Chima (polenta de milho branco) e frango a Zambeziana Foto: RIBEIRO, A.F.N., 2014.

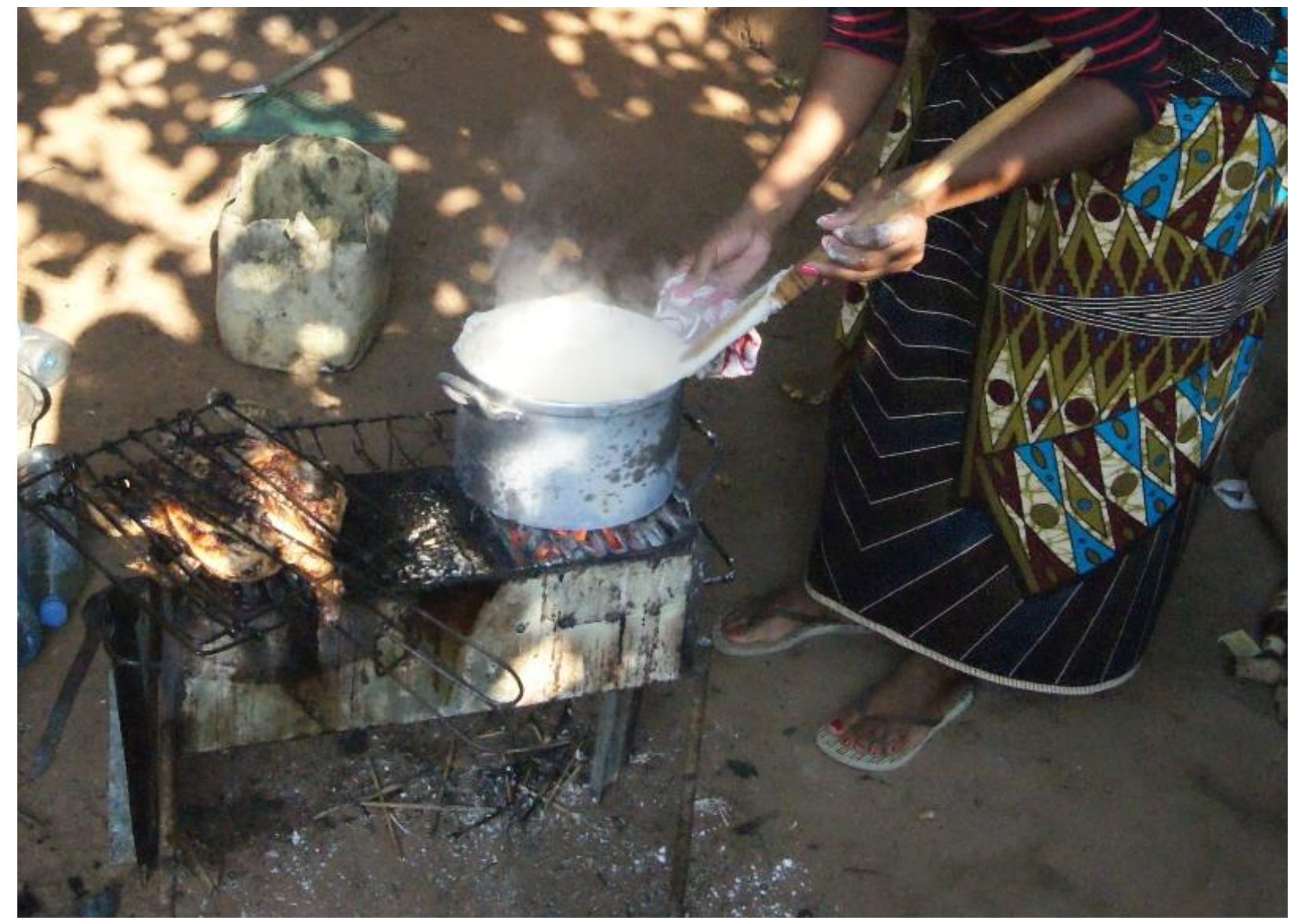

Posto isso, apresento a seguir um mapa com as visitas que fizemos neste primeiro momento que estivemos em Moçambique retratando o tema do projeto. 
Figura 7. Locais visitados pela equipe do projeto na primeira expedição a Moçambique.

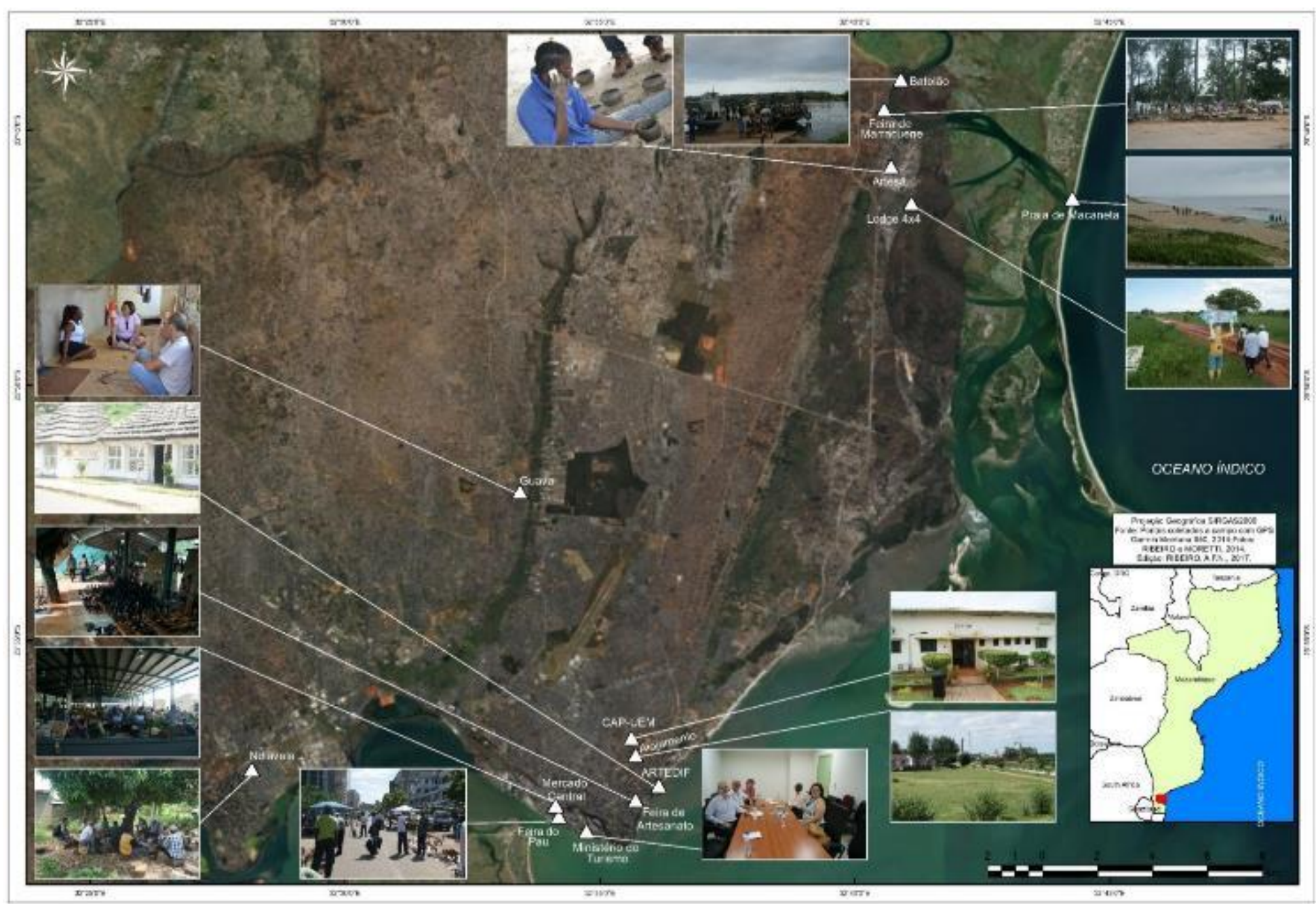


Neste mapa (figura 6) está concentrado a localização e imagens dos locais onde visitamos coletando informações sobre o tema da pesquisa e cada uma delas tem uma história curiosa, como a oficina de artesanato sob uma copa de mangueira, ou a artesã sentada ao chão produzindo panelas, enquanto seus filhos brincam no terreiro de casa, ou a sede da Associação de Artesão Deficientes (ARTEDIF), ou a feira de Marracuene com sua variedade de produtos e cores. Além das visitas técnicas aos artesãos fizemos várias reuniões com representantes do governo na área do turismo e representantes distritais com o intuito receber a autorização para as visitas do projeto.

Em Marracuene visitamos artesãos e o Lodge $4 \times 4$ que tem uma estrutura montada as margens do Rio Incomati com hospedagem temáticas e possibilidades de navegação no rio até a Praia de Macaneta.

Figura 8. Lodge 4x4 em Marracuene Foto: RIBEIRO, A.F.N., 2014.

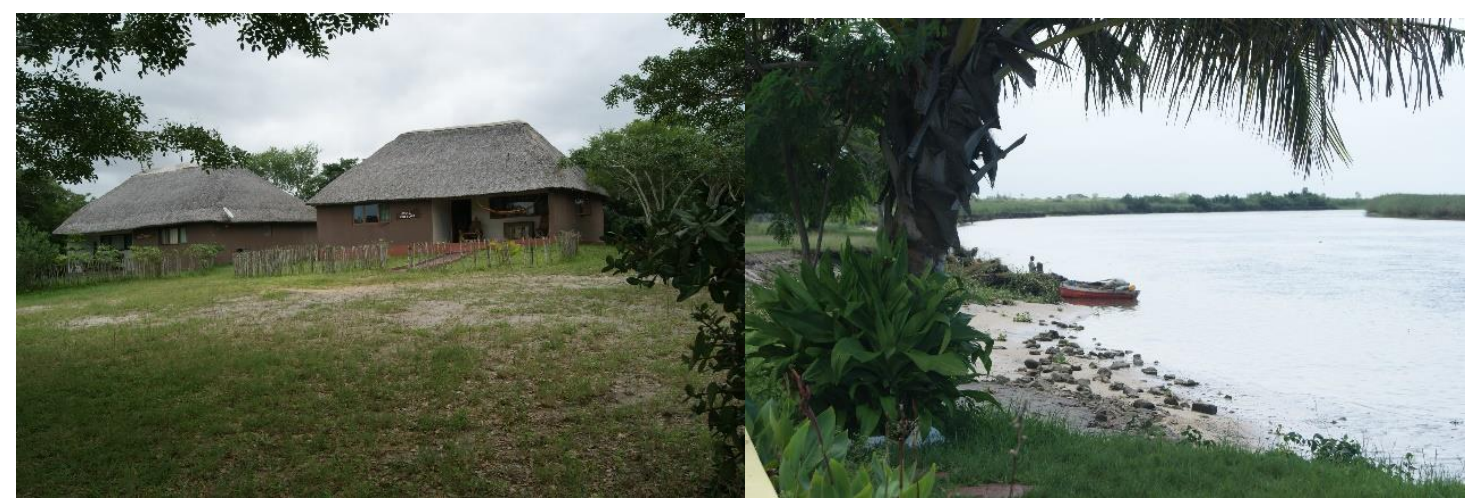

$\mathrm{Na}$ área urbana do distrito de Marracuene (Figura 9) acontece uma feira onde as pessoas comercializam artesanato, frutas, verduras, legumes e pequenos animais. 
Figura 9. Feira de Marracuene e suas peculiaridades Foto: RIBEIRO, A.F.N.,2014.
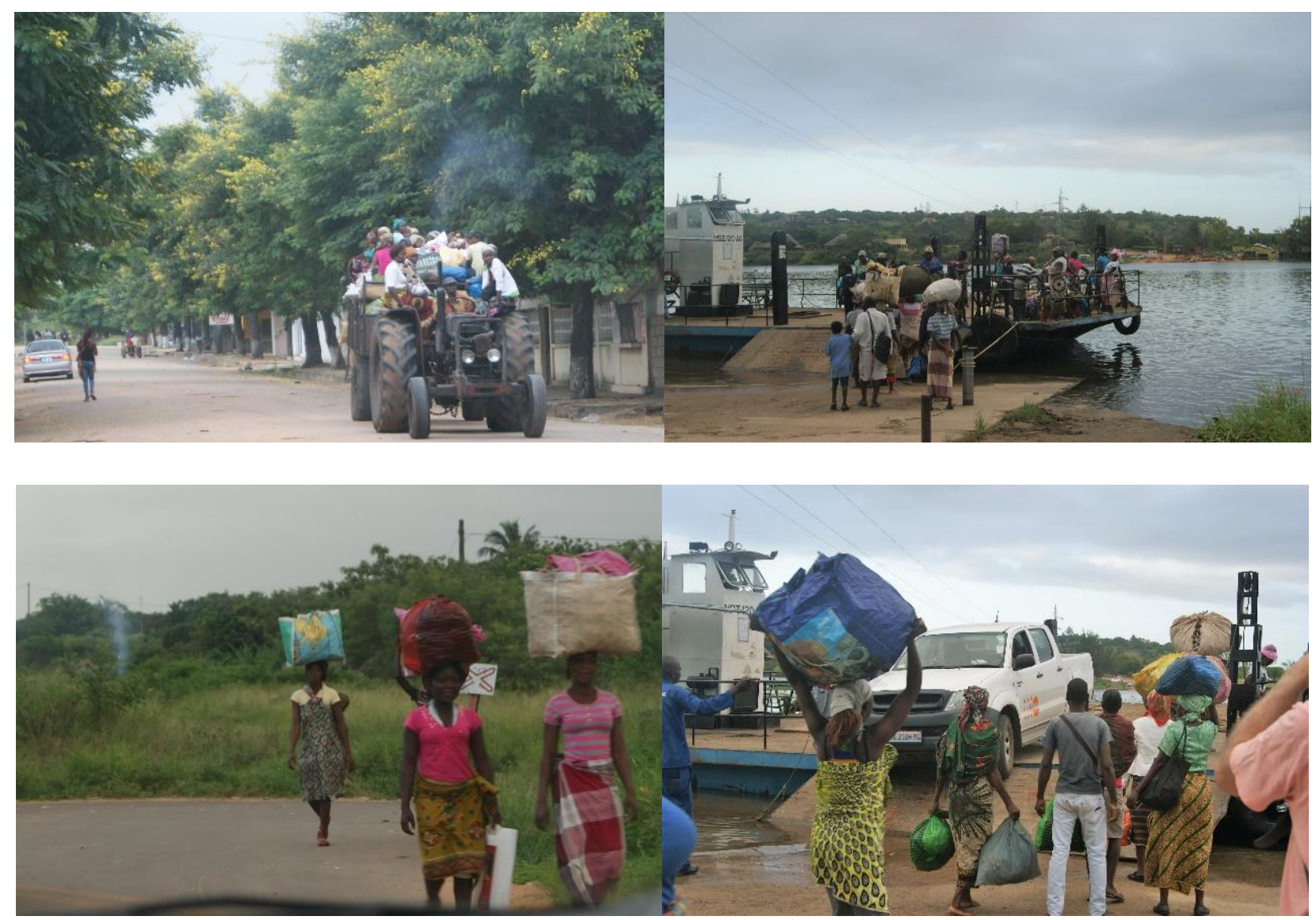

Caminhos para a Feira de Marracuene.

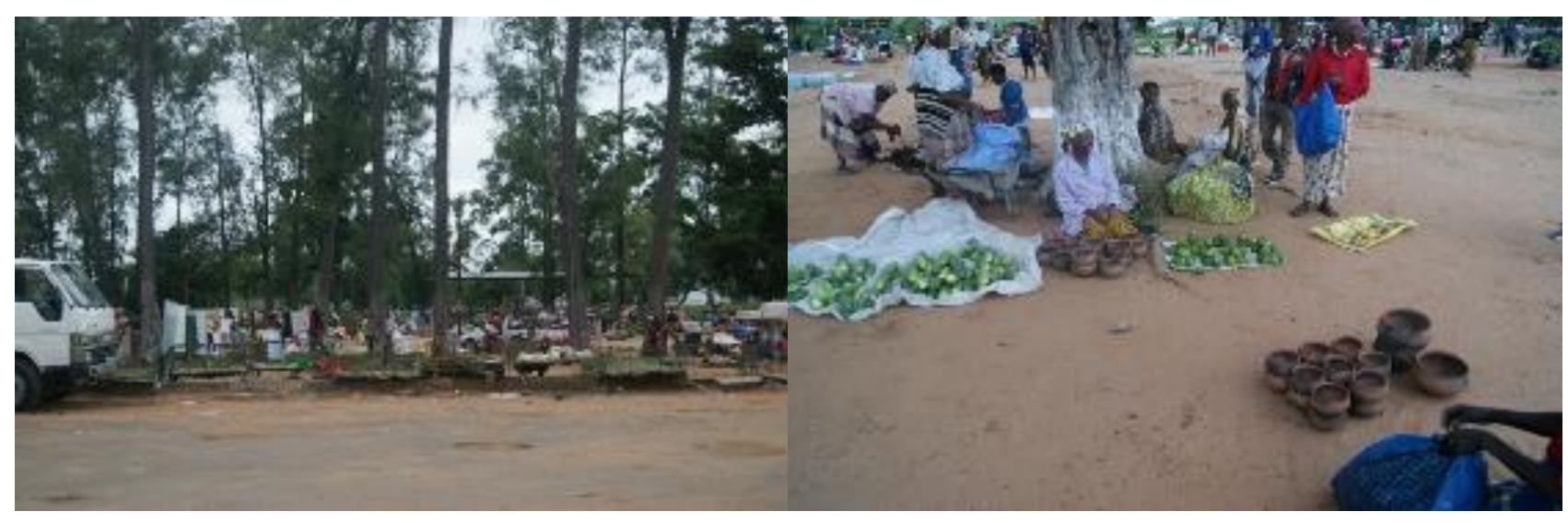

Feira de Marracuene. 
Figura 10. Localização do distrito de Marracuene

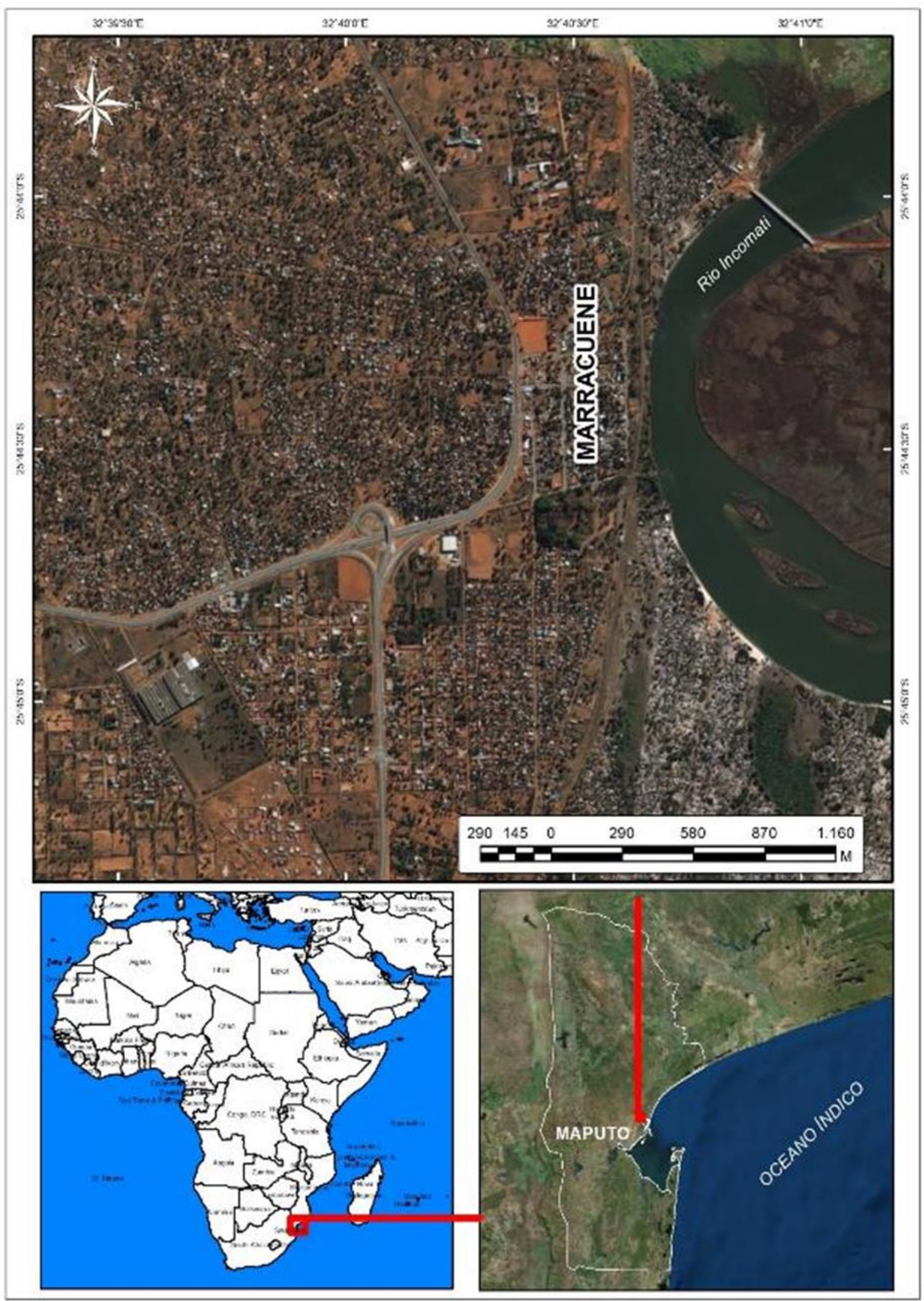


A diversidade de produtos presentes na mesa e à disposição nas feiras, mercados ou simplesmente nas bancas espalhadas em várias localidades nas casas além de garantir uma renda para as pessoas que vendem, oferece produtos frescos para o consumidor.

Figura 11. Banca de verduras e legumes. Foto: RIBEIRO, A.F.N.,2014.

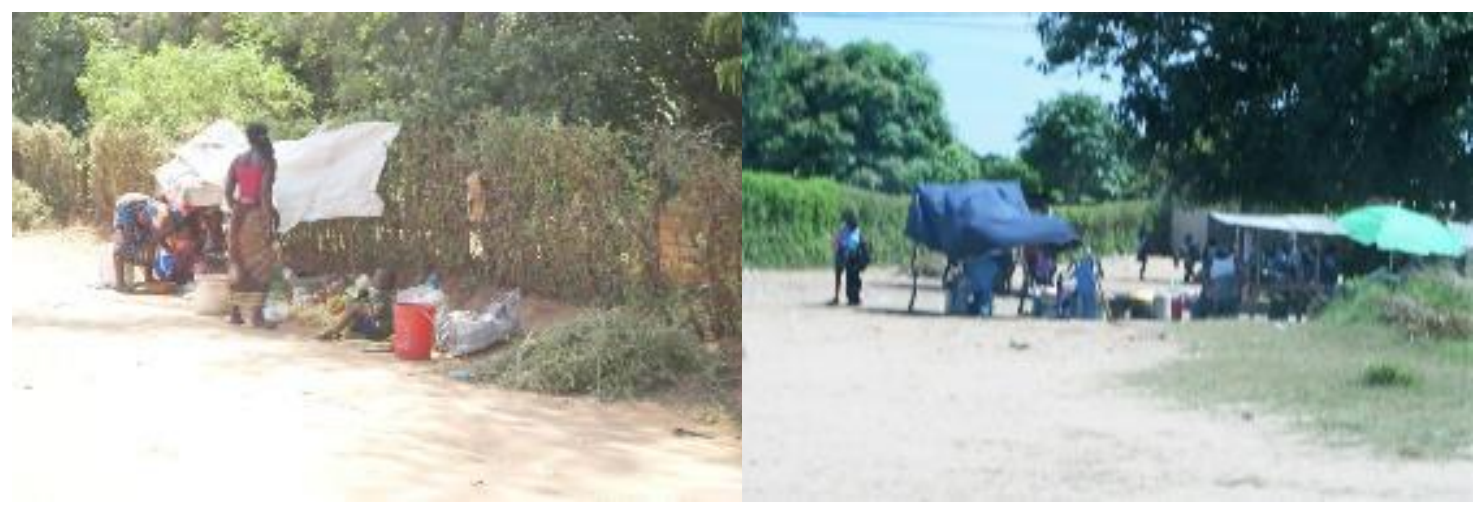

A variedade de pescado fresco encontrados nos mercados ou para aqueles que tiverem disponibilidade de ir na Praia de Macaneta, onde os pescadores vendem os peixes na praia ao tirar das redes. Esta praia fica próximo da Maputo, mas no momento em que estivemos teria que atravessar o rio Incomati com o Batelão (Balsa), mas quando a segunda expedição foi no ano de 2015 já existia ponte.

Figura 12. Pescadores na Praia de Macaneta Foto: RIBEIRO, A.F.N., 2014.

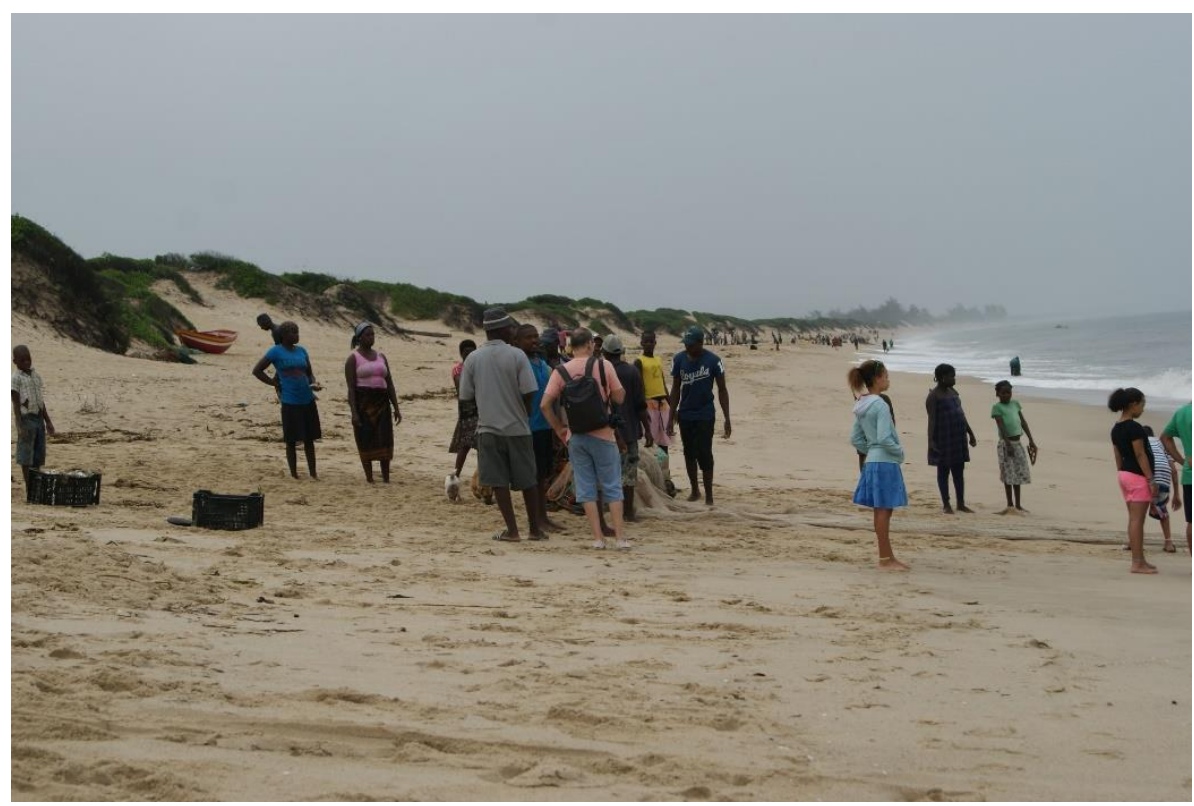


A diversidade do país também se mostra nas cores, da kapulana (tecido "coringa" que se adapta a várias formas de uso), lenços e roupas dos habitantes, ou também nos aspectos culturais, que percebemos que se mantém muito forte, na língua e costumes do povo originário, fato estranho ao Brasil, que de maneira avassaladora combate os costumes e línguas indígenas.

Os aspectos culturais são riquíssimos, no que diz respeito ao casamento, presenciamos em um sábado pela manhã, no Palácios dos Casamentos (algo semelhante no Brasil seria o Cartório) a celebração de vários casamentos e na saída dos noivos existe a figura dos animadores, que cantam e dançam desejando felicidades aos noivos, uma cerimônia muito emocionante.

Figura 13. Animadores de casamento cantando e dançando na saída dos noivos após o casamento Foto: RIBEIRO, A.F.N., 2014.

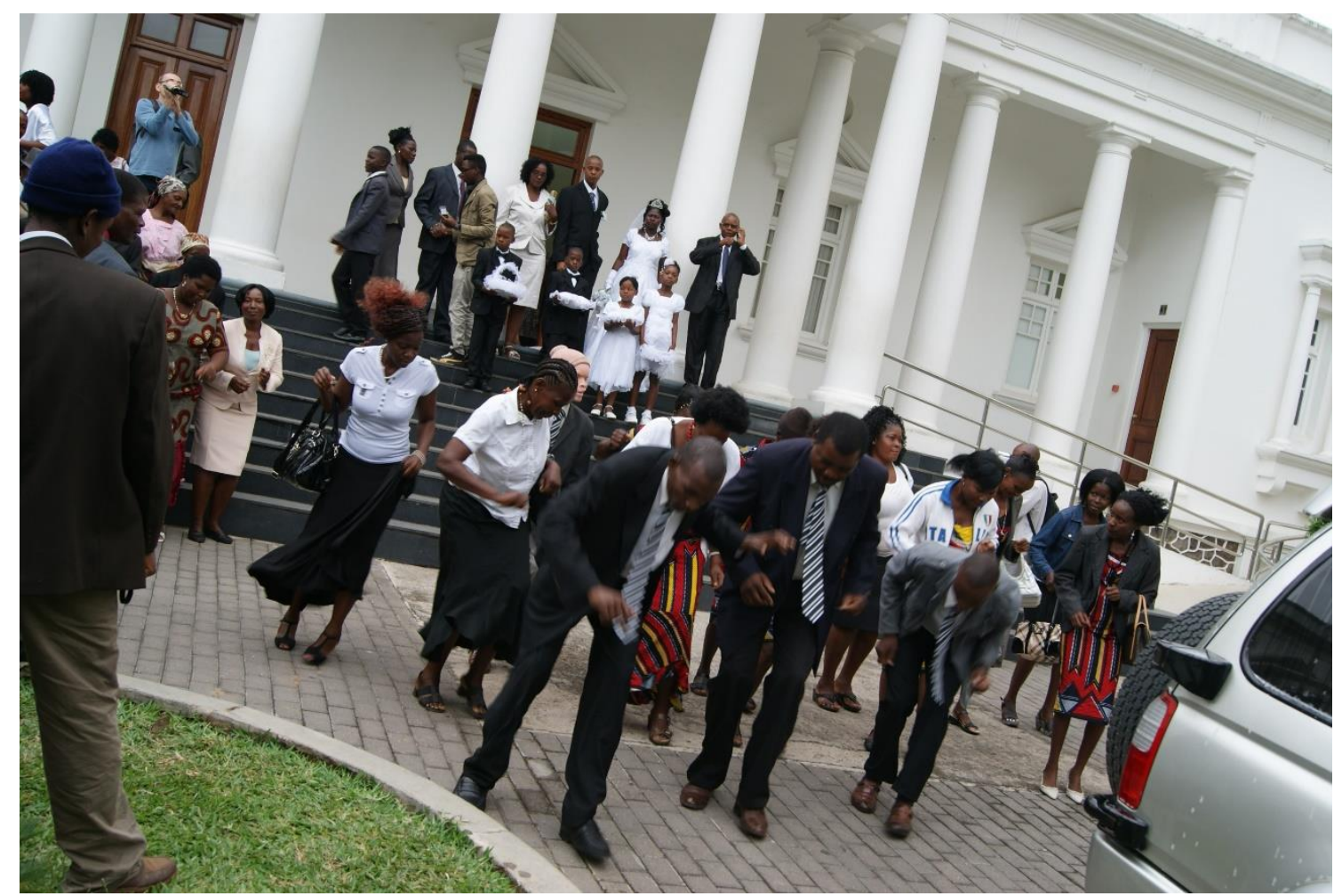

Além do quesito cultural da dança e canto ainda se tem a figura do dote (lobolo) que é um valor em dinheiro ou bem que a família da noiva recebe no ato do casamento para compensar a perda que é a saída dela da casa dos pais. 


\section{CONSIDERAÇÕES FINAIS}

Diante do exposto neste breve relato, esta experiência traz elementos importantes para o grupo de pesquisadores que estiveram nessa missão, e pessoalmente pela riqueza do convívio com pessoas deste continente tão estereotipado pelos meios de comunicação que chega as demais localidades.

A população é muito receptiva e alegre, mesmo diante das dificuldades que o país enfrenta sempre se mostram felizes e dispostos a ajudar as pessoas. Algo comum que percebemos no período em que estivemos em Maputo foi que, ao parar nos cruzamentos das ruas com "ares de perdido", sempre aparecia alguém disposto a ajudar.

Conhecer um país africano de maneira mais detalhada como tivemos a oportunidade de conhecer, e além disso conviver com pessoas da Universidade Eduardo Monldane e alunos que vieram para o Brasil em estágio ou para cursarem Pós-graduação até os dias atuais tem enriquecido muito a formação deste grupo de pesquisadores e alunos vinculados ao Laboratório de Pesquisas Territoriais da UFGD.

As informações que nos chega desta porção do planeta não representa a realidade vivenciada pelas pessoas que vivem lá, que ainda dependem de políticas inclusivas por parte dos governantes e que os países economicamente dominantes ao invés de extrair suas riquezas e escravizar sua população contribua com a melhoria nos serviços públicos e qualidade de vida dos moçambicanos.

Em suma, este projeto possibilitou, e ainda continua a manter este convênio entre a Universidade Federal da Grande Dourados/Brasil e Universidade Eduardo Mondlane/Moçambique, onde pesquisadores e alunos mantém contato e pesquisas resultantes deste projeto inicial.

A ciência tem como grande desafio nesta era digital desmistificar o discurso comum de oprimir as pessoas e buscar meios para que iniciativas como a deste projeto sejam conhecidas pelo maior número de pessoas possível e está publicação tem este papel.

\section{REFERÊNCIAS}

Portal do Governo de Moçambique. Informação Geral. Disponível em: <http://www.portaldogoverno.gov.mz/por >. Acesso em: 10 de fevereiro de 2018.

Censo de 2017. IV Recenseamento Geral da População e Habitação. Disponível em: <http://www.ine.gov.mz/operacoesestatisticas/censos/censo-2007/censo-2017/divulgacao-os-resultados-preliminares-iv-rgph-2017 >. Acesso em: 10 de março de 2018. 